\title{
Reduction mammoplasty improves body posture and decreases the perception of pain
}

\author{
Remi Goulart Jr MD¹, Daniele Detanico MSc² ${ }^{2}$ Roberta Pires Vasconcellos $\mathrm{MSc}^{2}$, \\ Gustavo Ricardo Schütz MSc², Saray Giovana dos Santos PhD²
}

R Goulart Jr, D Detanico, RP Vasconcellos, GR Schütz, SG dos Santos. Reduction mammoplasty improves body posture and decreases the perception of pain. Can J Plast Surg 2013;21(1):29-32.

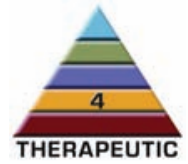

Women with hypertrophic breasts often experience body pain and posture problems, which tend to be reduced or even eliminated after reduction mammoplasty. The present study aimed to analyze the effects of reduction mammoplasty on anthropometric variables, body posture and pain in women with breast hypertrophy. Eleven women (mean $[ \pm \mathrm{SD}]$ age $31.3 \pm 10.4$ years) participated in the present study. Anthropometric variables, body posture and pain perception were evaluated pretest, and 60 (post 60 ) and 90 (post $_{90}$ ) days after reduction mammoplasty. Commercially available posture analysis software was used to analyze the following variables: acromial horizontal alignment (AHA), angle between acromial and anterior superior iliac spines (A-AAIS), vertical alignment of right (R) and left (L) trunk (VAT), vertical alignment of $\mathrm{R}$ and $\mathrm{L}$ body (VAB) and horizontal alignment of $R$ and $L$ pelvis (HAP). Descriptive statistics and ANOVA for repeated measures were used, and effect sizes (ES) were measured; the level of significance was set at $\mathrm{P}<0.05$. There were no significant differences in anthropometric variables among the assessments. Only HAP-R showed a significant decrease; however, when analyzed, ES, VAT- L and HAP- L in post $_{60}$, and VAT-R, VAT-L, HAP-R, HAP-L and VAB-L in post ${ }_{90}$ showed large ES after mammoplasty (ES $>0.70)$. There were significant reductions in pain at post ${ }_{60}$ and post $_{90}$ in the neck, cervical spine, back, shoulder and arm $(\mathrm{P}<0.05)$. Following mammoplasty, an improvement in body posture, primarily in the alignment of shoulders, trunk and pelvis, and a decrease in pain in the upper limbs and spine, were observed.

Key Words: Breast hypertrophy; Mammoplasty; Pain; Posture

$\mathrm{B}$ reast hypertrophy is defined as a disproportionate increase in breast size in relation to body size (1). This condition may lead to several social and psychological problems, such as low self-esteem and low quality of life (2-4), or even structural problems such as pain and musculoskeletal disorders (5-8).

According to Chao et al (3) and Freire et al (7), women with breast hypertrophy most frequently report pain in the neck, shoulder and lumbar spine, which may range from simple discomfort to functional disability. The origin or consequences of these symptoms may be due to postural alterations resulting in changes in the centre of gravity, which leads to exacerbation of the physiological curvatures of the cervical, thoracic and lumbar spines, and keeps the muscles of the neck and trunk excessively strained (9).

Benditte-Klepetko et al (10) found significant correlations among the perception of pain, breast size, body mass index (BMI) and postural deviations in the cervical and thoracic spine. These authors also indicated that even trying to maintain an upright posture can cause lumbar spine compensation and pelvic anteversion. Using radiographs, Findikcioglu et al (11) found that large breasts appear to alter normal thoracic kyphosis and lumbar lordosis angles; in addition, large breasts may cause degeneration of intervertebral discs of the cervical and thoracic spine (10). In contrast, postural alterations and muscle pain may be minimized or even eliminated

\section{La mammoplastie par réduction mammaire améliore la posture et réduit la perception de douleur}

Les femmes qui ont une hypertrophie mammaire ont souvent des douleurs et des problèmes de posture, qui ont tendance à diminuer ou même à disparấtre après une mammoplastie par réduction mammaire. La présente étude visait à analyser les effets d'une mammoplastie par réduction mammaire sur les variables anthropométriques, la posture et la douleur chez des femmes présentant une hypertrophie mammaire. Onze femmes (âge moyen [ \pm ÉT] de $31,3 \pm 10,4$ ans) ont participé à la présente étude. Les chercheurs ont évalué les variables anthropométriques, la posture et la perception de la douleur avant l'intervention, puis 60 jours (après 60 jours) et 90 jours (après 90 jours) après la mammoplastie par réduction mammaire. Les chercheurs ont utilisé un logiciel commercial d'analyse de la posture pour évaluer les variables suivantes : alignement horizontal acromial (AHA), angle entre les épines iliaques supérieures acromiales et antérieures (A-ÉIAAS), alignement vertical du tronc (AVT) du côté droit (D) et gauche $(\mathrm{G})$, alignement vertical du corps (AVC) du côté $\mathrm{D}$ et $\mathrm{G}$ et alignement horizontal du bassin (AHB) du côté $\mathrm{D}$ et $\mathrm{G}$. Ils ont utilisé les statistiques descriptives et l'analyse de variance pour les mesures répétées et mesuré l'ampleur de l'effet (AE). Ils ont établi le seuil de signification à $\mathrm{P}<0,05$. Il n'y avait pas de différence significative des variables anthropométriques entre les évaluations. Seul l'AHB-D a révélé une diminution importante, mais à l'analyse, l'AE, l'AVT-G et l'AHB-G après 60 jours, ainsi que l'AVT-D, l'AVT-G, l'AHB-D, l'AHB-G et l'AVC-G après 90 jours ont révélé une importante $\mathrm{AE}$ après la mammoplastie $(\mathrm{AE}>0,70)$. Les chercheurs ont constaté d'importantes réductions de la douleur dans le cou, la colonne cervicale, le dos, les épaules et les bras après 60 jours et 90 jours $(\mathrm{P}<0,05)$. Après la mammoplastie, on observait une amélioration de la posture, surtout dans l'alignement des épaules, du tronc et du bassin, et une diminution de la douleur dans les membres supérieurs et la colonne vertébrale.

following a surgical procedure for breast reduction known as reduction mammoplasty (3).

Previous studies have demonstrated improvement in women's body image and quality of life after reduction mammoplasty $(5,12-14)$. Freire et al (7) observed significant decreases in neck, shoulder and lumbar spine pain following reduction mammoplasty with removal of a mean of $1052 \mathrm{~g}$ of breast mass. Regarding body posture, Chao et al (3) verified significant improvement in the angles of rotation and translation of the head, and strength increases in the rhomboid, trapezius and major pectoral muscles six months after breast reduction even without rehabilitative physical exercise. Using static stabilometry, Tenna et al (15) recently reported improvement in postural control one and six months after breast reduction surgery.

No studies, however, have analyzed the effects of breast reduction on body composition, posture and pain perception because most investigations have focused solely on womens' perceptions of symptoms before and after the surgery. Understanding these effects may aid surgeons and professionals in recommending more concise postsurgery guidelines based on scientific evidence. Accordingly, the present study aimed to analyze the effects of reduction mammoplasty on anthropometric measurements, body posture and pain perception in women with breast

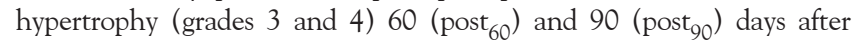
surgery.

\footnotetext{
${ }^{1}$ Specialist in Plastic Surgery by Brazilian Society of Plastic Surgery; São Francisco Hospital, Florianópolis; ${ }^{2}$ Biomechanics Laboratory, Federal

University of Santa Catarina, Florianópolis, Brazil

Correspondence: Ms Daniele Detanico, Biomechanics Laboratory, Federal University of Santa Catarina, Campus Trindade,

Florianópolis 88036-000, Brazil. Telephone 55-48-3721-8530, e-mail danieledetanico@gmail.com
} 
TABLE 1

Anthropometric variables in pretest, and 60 (post $_{60}$ ) and 90 (post $_{90}$ ) days after reduction mammoplasty

\begin{tabular}{llll}
\hline & Pretest & Post $_{60}$ & Post $_{90}$ \\
\hline Body mass, kg & $82.2 \pm 20.0$ & $81.7 \pm 19.8$ & $81.4 \pm 19.9$ \\
Height, $\mathrm{m}$ & $1.62 \pm 0.07$ & $1.62 \pm 0.07$ & $1.62 \pm 0.07$ \\
Body mass index, $\mathrm{kg} / \mathrm{m}^{2}$ & $31.4 \pm 7.9$ & $31.2 \pm 7.8$ & $31.1 \pm 7.8$ \\
\hline
\end{tabular}

Data presented a mean $\pm S D$

\section{METHODS}

\section{Participants}

Experiments were performed using one pretest and two post-tests. The pretest was conducted approximately 15 days before reduction mam-

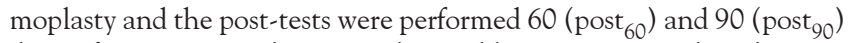
days after surgery. The control variables were surgical technique, physical activities, daily activities and the use of a special brassiere after surgery. The patients used pain or anti-inflammatory medications during the first month after the surgery when necessary. However, during the assessments (ie, 60 [post ${ }_{60}$ ] and 90 [post ${ }_{90}$ ] days after surgery), the patients did not use any pain medication.

Eleven women comprised the experimental group (mean $[ \pm \mathrm{SD}]$ age $31.3 \pm 10.4$ years). They were selected based on the following criteria: $>18$ years of age; breast hypertrophy grade 3 or 4 ; and signing an informed consent form and pledging to perform all pre- and postsurgery assessments and adhere to medical recommendations after surgery. All procedures were approved by the Ethics Committee of the Federal University of Santa Catarina, Florianópolis, Brazil (protocol 1943/2011), in accordance with the Declaration of Helsinki.

\section{Procedures}

Anthropometric variables: To measure participants' body mass and height, a digital scale (capacity $150 \mathrm{~kg}$, precision $100 \mathrm{~g}$ [Toledo, USA]) and a portable stadiometer $(200 \mathrm{~cm}$ and $1 \mathrm{~mm}$ precision [Model 220, Seca, United Kingdom), respectively, were used. BMI was calculated using the following formula:

$$
\mathrm{BMI}=\text { Body mass }(\mathrm{kg}) / \text { height }(\mathrm{m})^{2},
$$

These variables, especially BMI, have been widely used in previous studies to measure body composition and to identify the presence of obesity $(4,5,7,10,11,14,15)$.

Body posture: Postural assessment software (SAPO, São Paolo University, Brazil) was used for postural analysis. The inter-rater reliability (reproducibility) of the SAPO software was previously verified by intraclass correlation coefficient and ranged from 0.81 to 0.97 for the measurements analyzed in the present study; angle and distance validity also showed good accuracy $\left(0.11^{\circ}\right.$ and $1.8 \mathrm{~mm}$, respectively) (16).

Women were initially instructed to remain in an orthostatic position wearing few clothes (bathing suit, or top and lycra shorts) and next to a plumbline. The following anatomical points were marked according to the SAPO protocol: temporomandibular joint, acromion, anteriorsuperior iliac spine, greater trochanter, knee joint line, patella medial point, tibia tuberosity, medial malleolus, lateral malleolus, point between the head of second and third metatarsal, C7 spinous process, T3 spinous process, scapula lower angle and posterior-superior iliac spine.

After labelling the anatomical points, images were captured in the anterior, right lateral and left lateral view of the body using a digital camera (A590, Canon, USA) attached to a tripod at a height of $1 \mathrm{~m}$ and located $3 \mathrm{~m}$ from the subjects. For image analysis, the SAPO protocol was used and the following variables were investigated: anterior view - acromial horizontal alignment (AHA) and angle between acromial and anterior superior iliac spines (A-AAIS); and lateral view - vertical alignment of the trunk, right (R) and left (L) (VAT), vertical alignment of the body (VAB), R and L, and horizontal alignment of the pelvis (HAP), R and L.
Perception of body pain: A scale structured according to a map of body parts was used to assess body pain/discomfort. This scale measured the occurrence of discomfort or pain in seven areas of the trunk and upper limbs, namely, the neck, cervical spine, upper back, medial back, lower back, shoulder and arm. These body parts were chosen because, according to previous studies $(2,3,5,7)$, they are the most commonly cited to be symptomatic by women with breast hypertrophy. The women marked the intensity of pain/discomfort perceived in each body part on a continuous scale ranging from 0 (no discomfort or pain) to 9 (very high discomfort or pain).

\section{Reduction mammoplasty}

Surgical procedures were performed by combining an inferior dermoglandular pedicle with an inverted-T scar reduction mammoplasty as described by Ribeiro and Backer (17). To characterize the degree of breast hypertrophy, the Maliniac (18) description was used: grade 3 represents the removal of $500 \mathrm{~g}$ to $1500 \mathrm{~g}$ of excess glandular-adipose tissue during breast reduction, while grade 4 represents the removal of $>1500 \mathrm{~g}$ of excess glandular-adipose tissue.

\section{Statistical analysis}

Data are reported as mean \pm SD. Data normality was verified by the Shapiro-Wilk test and the homogeneity of variance was verified using Levene's test. To compare anthropometric measurements, body posture and pain perception among the pretest, post $_{60}$ and post ${ }_{90}$ assessments, the ANOVA for repeated measures was used with the Bonferroni post hoc test and the level of significance was set at $\mathrm{P}<0.05$.

In addition, the effect size (ES) was used to be more sensitive to intervention effects than conventional inferential statistics (19). GPower 3.1 (University of Kiel, Germany) was used to perform calculations. For ES classification, the criteria established by Cohen (19) $(<0.41$ [small]; 0.41 to 0.70 [moderate]; and $>0.70$ [large effect]) were used.

\section{RESULTS}

The patients in the present study had a mean of $1848.0 \pm 776.3 \mathrm{~g}$ of total breast mass removed, with a mean of $979.0 \pm 456.5 \mathrm{~g}$ removed from the right breast and $869.0 \pm 776.3 \mathrm{~g}$ removed from the left breast.

Table 1 summarizes the anthropometric variables in the pretest, post $_{60}$ and post $_{90}$ after the reduction mammoplasty. No significant differences were found among the pretest and other evaluations for any variables.

Angular values of body posture in the pretest, post $_{60}$ and post ${ }_{90}$ are reported in Table 2. Negative values indicate postural deviations to the left and positive values indicate postural deviations to the right. However, for comparisons, the values in the module were used. A significant difference was observed only for HAP-R.

When using ES to verify the effects of reduction mammoplasty on body posture, VAT-L and HAP-L at post $_{60}$, VAT-R, VAT-L, HAP-R, HAP-L and VAB-L at post $90(E S>0.70)$ showed large effects, while AHA ( post $_{90}$ ), A-AAIS ( post $_{60}$ and post $_{90}$ ), VAT-R (post 60 ) and HAP-R (post 60 ) (ES 0.41 to 0.70 ) showed moderate effects after surgery (Table 3$)$.

Figure 1 presents the pain perception scale scores the pretest, post $_{60}$ and post $_{90}$ analyses. There were significant decreases in pain among pretest, post $_{60}$ and post ${ }_{90}$ data in all body parts (neck, cervical spine, back, shoulder and arm); however, there were no significant differences between post ${ }_{60}$ and post $_{90}$ for any body part. In general, pain scale values were extremely high in the pretest $(7.0 \pm 1.3)$, and decreased to $1.4 \pm 0.4$ at post $_{60}$ and $0.8 \pm 0.5$ at post $_{90}$.

\section{DISCUSSION}

The present study investigated the effects of reduction mammoplasty on anthropometric variables, body posture and pain perception. Regarding the anthropometric variables, there were no significant differences in body mass and BMI after surgery, indicating that despite breast mass reduction, women retained their body mass and BMI. This was probably due to the recovery period, in which patients stayed home and avoided upper limb movements, which led to lower energy expenditure and, 
TABLE 2

Angular values of body posture in pretest, and 60 (post ${ }_{60}$ ) and 90 (post $_{90}$ ) days after breast reduction mammoplasty

\begin{tabular}{|c|c|c|c|}
\hline Posture variable, $^{\circ}$ & Pretest & Post $_{60}$ & Post $_{90}$ \\
\hline $\mathrm{AHA}$ & $0.64 \pm 0.5$ & $0.46 \pm 0.6$ & $0.36 \pm 0.4$ \\
\hline A-AAIS & $-0.72 \pm 0.4$ & $-0.45 \pm 0.6$ & $-0.18 \pm 0.9$ \\
\hline HAP-R & $-11.5 \pm 2.0$ & $-10.5 \pm 2.4$ & $-8.27 \pm 1.7^{*}$ \\
\hline HAP-L & $12.0 \pm 1.6$ & $9.36 \pm 1.4$ & $10.5 \pm 2.0$ \\
\hline VAT-R & $-2.36 \pm 0.9$ & $-2.0 \pm 0.8$ & $-1.27 \pm 0.6$ \\
\hline VAT-L & $-3.90 \pm 0.9$ & $-2.46 \pm 1.2$ & $-2.09 \pm 0.7$ \\
\hline VAB-R & $-0.18 \pm 0.3$ & $-0.09 \pm 0.4$ & $0.09 \pm 0.3$ \\
\hline VAB-L & $-0.55 \pm 0.3$ & $-0.46 \pm 0.4$ & $-0.27 \pm 0.2$ \\
\hline
\end{tabular}

Data presented as mean $\pm S D$. Negative values indicate postural deviations to the left and positive values to the right. ${ }^{*} P<0.05$ (difference between pretest and post ${ }_{90}$ ). A-AAIS Angle between acromial and anterior-superior iliac spines; AHA Acromial horizontal alignment; HAP Horizontal alignment of the pelvis; $L$ Left; R Right; VAB Vertical alignment of the body; VAT Vertical alignment of the trunk

consequently, to increases in body mass. Dietary consumption may have also influenced these variables; however, this particular variable was not controlled.

BMI values were classified as 'obesity level 1' according to the WHO. Previous studies $(4,11,14)$ have also verified higher BMI values in women with breast hypertrophy.

Obesity itself is a risk factor for several musculoskeletal disorders such as postural (20) and equilibrium (21) problems, osteoarthritis (22) and reduced knee functional capacity (23). However, according to Benditte-Klepetko et al (10), when combined with breast hypertrophy, these problems are amplified when changes in the centre of gravity, postural deviations in the cervical and thoracic spines, and a decrease of motion amplitudes in the upper limbs are diagnosed.

Regarding body posture and comparing the three assessments, only HAP-R demonstrated significant improvement; however, when analyzing ES, VAT-L and HAP-L in the post ${ }_{60}$, and VAT-R, VAT-R, HAP$\mathrm{R}$, HAP-L and VAB-L in the post $_{90}$, showed large effects after mammoplasty. Moreover, AHA ( post $_{90}$ ), A-AAIS ( post $_{60}$ and post $_{90}$ ), VAT-D ( post $_{60}$ ) and HAP-D ( post $_{60}$ ) showed moderate effects.

Following surgery, women achieved some improvement in pelvic horizontal alignment on the lateral view, both left and right. Negative values for the right side and positive values for the left can be interpreted as pelvic anteversion. With excessive breast mass, the natural tendency is to locate the centre of gravity forward $(10,11)$; therefore, muscular adjustment, such as pelvic anteversion, may occur to maintain body balance. According to Magee (24), this postural deviation is usually accompanied by lumbar hyperlordosis, which is caused by shortening of the hip flexor muscles and tensor fasciae latae combined with stretching of the abdominal muscles. Furthermore, Ribeiro et al (25) indicated that pelvic misalignment induces additional strain on the joints, causing soft tissue stretching, and decreases muscle and ligament efficiency, which are responsible for joint balancing. On the other hand, the improvement in pelvic alignment after reduction mammoplasty may reduce joint overload in the lower limbs and concomitantly increase muscle-joint efficiency.

Other variables that showed a large effect after reduction mammoplasty were VAT and VAB (acromion point to the lateral malleolus) in the lateral view. Negative values on the right indicate anterior displacement of the trunk, while values to the left indicate posterior displacement of the trunk. This could be explained by the differences found in the amount of breast mass removed because more breast volume was removed from the right side than from the left.

With breast volume reduction, there was a decrease in sustained load to the shoulders, which generated the characteristic of anterior shoulders, especially on the right side, similar to what has been reported in previous studies $(9,10)$. According to Magee (24), this is primarily due to the stretching of the lower and medium trapezius
TABLE 3

Absolute differences between pretest and 60 (post $_{60}$ ), pretest and 90 (post $_{90}$ ), and associated effect size (ES)

\begin{tabular}{|c|c|c|c|c|}
\hline Variable, $^{\circ}$ & $\begin{array}{c}\text { Difference pretest } \\
\text { and } \text { post }_{60}\end{array}$ & ES & $\begin{array}{l}\text { Difference pretest } \\
\text { and post } \\
90\end{array}$ & ES \\
\hline $\mathrm{AHA}$ & 0.18 & 0.39 & 0.28 & 0.61 \\
\hline A-AAIS & 0.27 & 0.51 & 0.54 & 0.69 \\
\hline HAP-R & 1.00 & 0.68 & 3.23 & 1.88 \\
\hline HAP-L & 2.64 & 1.75 & 1.50 & 0.82 \\
\hline VAT-R & 0.36 & 0.42 & 0.73 & 1.54 \\
\hline VAT-L & 1.44 & 1.33 & 1.81 & 2.21 \\
\hline VAB-R & 0.09 & 0.25 & 0.09 & 0.30 \\
\hline VAB-L & 0.09 & 0.25 & 0.28 & 0.88 \\
\hline
\end{tabular}

A-AAIS Angle between acromial and anterior-superior iliac spines; AHA Acromial horizontal alignment; HAP Horizontal alignment of the pelvis; L Left; R Right; VAB Vertical alignment of the body; VAT Vertical alignment of the trunk

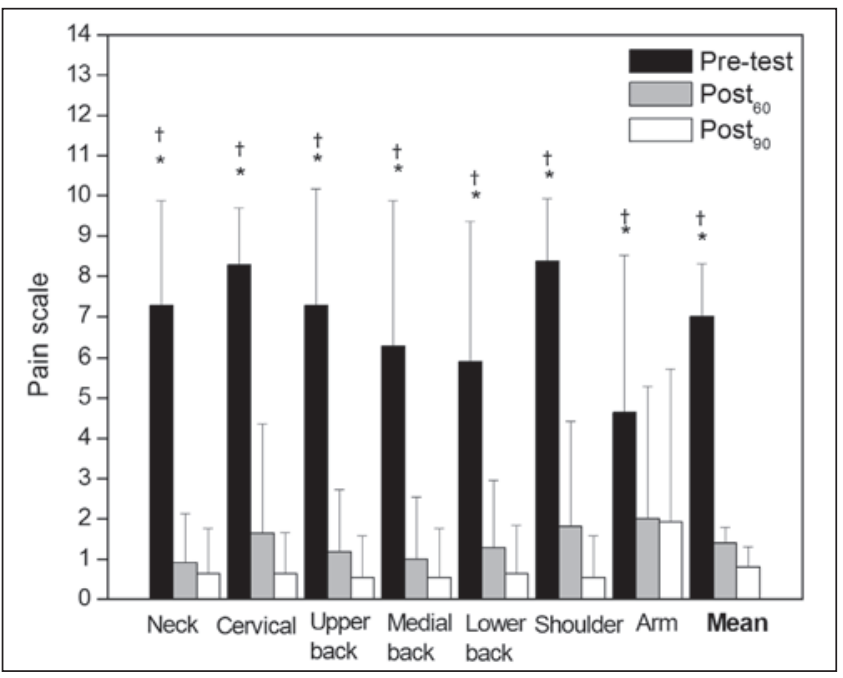

Figure 1) Perception of body pain in pretest, and $60\left(\right.$ Post $\left._{60}\right)$ and 90 $\left(\right.$ Post $_{90}$ ) days after breast reduction mammoplasty. $* P<0.05$ (Difference between pretest and post ${ }_{60}$ ); ${ }^{\dagger} P<0.05$ (Difference between pretest and post $_{90}$ )

muscles, and shortening of the minor pectorals and superior trapezius. After surgery, the acromion becomes more aligned in relation to the hips and lateral malleolus. Thus, there was improvement not only in trunk alignment but also in the vertical alignment of both sides of the entire body.

Breast reduction also had a moderate effect on AHA and A-AAIS. Given that the patients did not undergo any type of postural re-education or rehabilitative physical exercise, we speculate that these improvements were due to greater symmetry in breast volume after surgery.

There was a significant decrease in pain perception between the pretest and other evaluations (ie, post 60 and post ${ }_{90}$ ) in all body segments. Body pain scale values for the the neck, back, shoulders and arms showed extremely high pretest vales (7.0) but were reduced to 1.4 at post $_{60}$ and 0.8 at post $_{90}$.

Pretest results with high levels of back pain or discomfort were also observed by Fernandes et al (4), who used a numerical scale to assess pain intensity ranging from 0 to 10 , and reported mean pain values of $5.5,6.5$ and 6.2 for the cervical, thoracic and lumbar spines, respectively. Benditte-Klepetko et al (10) showed a positive correlation between breast weight and back pain, even when age and BMI were controlled for. Pernia et al (26) indicated that pain in the shoulders and arms may be caused by compression of the brachial plexus between the coracoid process of the scapula and chest cavity through shoulder depression both forward and down.

In contrast to these findings, Wood et al (8) evaluated 30 women between 18 and 26 years of age and found a negative correlation 
between breast size and pain incidence/intensity in the thoracic spine, suggesting that only $4 \%$ of the variation in pain scores may be attributed to breast size. However, the authors highlighted that characteristics of this particular age group may have influenced the results. In this regard, Sigurdson et al (27) stated that symptoms corresponding to physical pain in older women were more common, while psychological problems predominate in younger women.

A study by Letterman and Schurter (9) verified that lumbar pain may be completely eliminated or considerably reduced after reduction mammoplasty. Body pain scale scores decreased from 7.0 to 0.8 points (ie, the patients reported a large reduction in pain perception for different body parts). Similar results were reported by Blomqvist et al (5), who identified average scores from 6 to 7 (on a scale from 0 to 10) for neck, shoulder and back pain before surgery. Six months after the surgery, the maximum values of pain were 2.5 in all body parts and, after 12 months, decreased by approximately $90 \%$ compared with the presurgical evaluation, with values $<2$.

Chao et al (3) observed a significant reduction (5.7 points) in pain scale scores six months after surgery, and Ducic et al (28) found a significant reduction in the frequency and intensity of pain in the head ( 7.2 to 3.2), back, neck and shoulders (7.5 to 4.1 ), and a significant improvement in patients' quality of life following reduction mammoplasty.

The excessive weight of hypertrophic breasts acts as a downward lever, resulting in greater strain on the neck and posterior trapezius muscles and, consequently, compromises the stabilizing strength of these body parts (29). The repetitive nature of this event may cause hyperexcitability of peripheral nociceptors and increase central

\section{REFERENCES}

1. Tafuri LS, Gobbi H. Epithelial hyperplasia in specimens from bilateral reduction aesthetic mammaplasty and reduction mammaplasty contralateral to breast cancer. J Bras Patol Med Lab 2005;41:135-41.

2. Araújo CDM, Gomes HC, Veiga DF, et al. Influence of breast hypertrophy in the women's functional capacity. Braz J Rheumatol 2007;47:91-6

3. Chao JD, Memmel HC, Redding JF, Egan L, Odom LC, Casas LA. Reduction mammaplasty is a functional operation, improving quality of life symptomatic women: A prospective, single-center breast reduction outcome study. Plast Reconstr Surg 2002;110:1644-52

4. Fernandes PM, Neto MS, Veiga DF, et al. Dores na coluna: Avaliação em pacientes com hipertrofia mamária. Acta Ortop Bras 2007;15:227-30.

5. Blomqvist 1, Eriksson A, Brandberg Y. Reduction mammaplasty provides long-term improvement in health status and quality of life. Plast Reconstr Surg 2000;106:991-7.

6. Fouquet B, Goupille P, Rouif M, Rouif V, Mateu J, Valat JP. Breast hypertrophy and dorsolumbar spine. Prognostic influences of lumbar lordosis: Preliminary results. Rev Rhum Mal Osteoartic 1991;58:453-7

7. Freire M, Meto MS, Garcia EB, Quaresma MR, Ferreira RM. Functional capacity and postural pain outcomes after reduction mammaplasty. Plast Reconstr Surg 2007;119:1149-56.

8. Wood K, Cameron M, Fitzgerald K. Breast size, bra fit and thoracic pain in young women: A correlational study. Chiropr Osteopat 2008;13:16-21.

9. Letterman G, Schurter M. The effects of mammary hypertrophy on the skeletal system. Ann Plast Surg 1980;5:425-31.

10. Benditte-Klepetko H, Leisser V, Paternostro-Sluga T, et al. Hypertrophy of the breast: A problem of beauty or health? J Women's Health 2007;16:1062-9.

11. Findikcioglu K, Findikcioglu F, Ozmen S, Guclu T. The impact of breast size on the vertebral column: A radiologic study. Aesth Plast Surg 2007;31:23-7.

12. Birtchnell S, Whitfield P, Lacey JH. Motivational factors in women requesting augmentation and reduction mammaplasty. J Sychosom Res 1990;34:509-14

13. Borkenhagen A, Röhricht F, Preib S, Schneider W, Brähler E. Changes in body image and health-related quality of life following breast reduction surgery in German macromastia patients: A new tool for measuring body image changes. Ann Plast Surg 2007:58:364-70.

14. Spector JA, Singh SP, Karp NS. Outcomes after breast reduction: Does size really matter? Ann Plast Surg 2008;60:505-9. sensitivity (28). Thus, it is believed that the reduction in the frequency and intensity of pain reported by patients may be attributed to the reduction of pressure on the occipital nerve, due to improving postural alignment, as previously discussed.

The absence of statistical differences between the post 60 and post ${ }_{90}$ evaluations was also observed by Blomqvist et al (5), who performed postsurgery assessment 12 months after reduction mammoplasty, although the pain values (2.0) were higher than findings from the present study (0.8) obtained 90 days after surgery. One possible explanation may be the amount of breast mass removed in each study ( $1848.0 \mathrm{~g}$ in the present study versus $1052.0 \mathrm{~g}$ in Blomqvist et al [5]) and the BMI before mammoplasty $\left(31.4 \mathrm{~kg} / \mathrm{m}^{2}\right.$ to $24.4 \mathrm{~kg} / \mathrm{m}^{2}$, respectively). According to Collins et al (30), patients with more severe musculoskeletal problems as a result of breast hypertrophy tend to respond more positively and more rapidly to surgical intervention.

\section{CONCLUSIONS}

Reduction mammoplasty improved body posture primarily in the alignment of the shoulders, trunk and pelvis. Moreover, a reduction in pain in the upper limbs and spine was found 60 and 90 days following surgery. These improvements reflect positively on patient health and quality of life because it helps in the adoption of more appropriate body posture and mitigates stress to the musculoskeletal system.

DISLCOSURES: The authors have no financial disclosures or conflicts of interest to declare.

15. Tenna S, Brunetti B, Trivelli M, Salvinelli F, Persichetti P Postural variations after breast reduction. Ann Plast Surg 2012;68:261-4

16. Ferreira EAG, Duarte M, Maldonado EP, Burke TN, Marques AP. Postural assessment software (PAS/SAPO): Validation and reliability. Clinics 2010;65:675-81.

17. Ribeiro E, Backer E. Mastoplastia con pedículo de seguridad. Rev Esp Cir Plast 1973;16:223-34.

18. Maliniac JW. Breast deformities and their repair. J Am Med Assoc 1950;144:282

19. Cohen J. Statistical Power Analysis for the Behavioral Sciences. Hillsdale: Lawrence Earlbaum Associates, 1988.

20. Hooper MM. Tending to the musculoskeletal problems of obesity. Clev Clin J Med 2006;73:839-45.

21. Francisco CO, Okada VT, Ricci NA, Benze BG, Rebelatto JB, Duarte AC. Body balance comparison between obese and nonobese women from middle-age on. Phys Therapy Res 2009;16:323-8.

22. Chacur EP, Silva LO, Luz GCP, Silva PL, Baraúna MA, Cheik NC. Obesity and its correlation with knee osteoarthritis in adult women. Phys Therapy Mov 2008;21:93-8.

23. Vasconcellos KSS, Dias JMD, Dias RC. Impact of the degree of obesity on symptoms and functional capacity of women with knee osteoarthritis. Phys Therapy Res 2008;15:125-30.

24. Magee DJ. Orthopedic Physical Assessment. St Louis: WB Saunders Company, 2008.

25. Ribeiro CZ, Akashi PM, Sacco IC, Pedrinelli A. Relationship between postural changes and injuries of the locomotor system in indoor soccer athletes. Bras J Sports Med 2003;9:98-103.

26. Pernia LR, Ronel DN, Leeper JD, Miller HL. Carpal tunnel syndrome in women undergoing reduction mammaplasty. Plast Reconstr Surg 2000;105:314.

27. Sigurdson L, Mykhalovskiy E, Kirkland SA, Pallen A. Symptoms and related severity experienced by women with breast hypertrophy. Plast Reconstr Surg 2007;119:481-6.

28. Ducic I, Iorio ML, Al-Attar A. Chronic headaches/migraines: Extending indications for breast reduction. Plast Reconstr Surg 2010;125:44-9.

29. Guyuron B, Kriegler JS, Davis J, Amini SB. Comprehensive surgical treatment of migraine headaches. Plast Reconstr Surg 2005;115:1-9.

30. Collins ED, Kerrigan CL, Kim M, et al. The effectiveness of surgical and nonsurgical interventions in relieving the symptoms of macromastia. Plast Reconstr Surg 2002;109:1556-66. 